\title{
Analysis of cold spells in the Greek region
}

\author{
C. Pappas, N. Hatzianastassiou* , B. D. Katsoulis \\ Laboratory of Meteorology, Department of Physics, University of Ioannina, 45110, Ioannina, Greece
}

\begin{abstract}
The extreme phenomenon of cold-spell events in the Greek region was investigated in this study by using a combined deterministic-stochastic model, along with $31 \mathrm{yr}$ daily minimum temperature data from 16 meteorological stations of the Hellenic National Meteorological Service (HNMS). Trend analysis and the spatio-temporal distribution of cold spells were investigated by applying linear regression and Fourier analysis. The frequency, duration, distribution, timing and intensity of cold spells were successfully fitted with Poisson, Gauss and exponential distributions. The features of cold spells were found to vary widely, due to the effect of physicogeographical parameters such as latitude, longitude, altitude, and continentality, as well as to the synoptic weather situations prevailing in the various Greek sub-areas. The relative importance of the physicogeographical peculiarities was assessed: latitude and altitude were evaluated as the most important parameters for determining the features of cold spells in Greece. The highest probability of cold spells in the Greek peninsula exists when a persistent NW European and/or Siberian anticyclone reaches its highest intensity during winter and extends high-pressure ridges to the Balkans, and particularly to the Greek area.
\end{abstract}

KEY WORDS: Extreme events $\cdot$ Cold spell $\cdot$ Frequency $\cdot$ Timing $\cdot$ Magnitude $\cdot$ Statistical distributions Resale or republication not permitted without written consent of the publisher

\section{INTRODUCTION}

Variations and trends in extreme weather and climatic events have received much attention in the last few years, due to the frequently large loss of human life, increasing agricultural damage and other harmful economic impacts associated with them (IPCC 2001). Knowledge of the risks of extreme (high or low) temperatures is important for many human activities, particularly those related to domestic consumption of energy and outdoor activities (e.g. agriculture, transportation, and tourism; Sanderson 1983). It follows that the analysis and prediction of extreme cold spells and the relevant synoptic conditions that favour their development, frequency, intensity and duration constitutes an important field of study (e.g. Karapiperis 1964, Barry \& Perry 1973, Landsberg 1977, Brody \& Nestor 1980, Plummer et al. 1999).

Greece is a suitable region for studying the spatio-temporal variability of cold-spell characteristics because of its fairly large north-to-south extent, the complex topography with plains, mountains, coasts and the large number of islands providing a diversity of geographical conditions (Fig. 1).

The minimum temperature below which damage occurs varies with the outdoor activity and timing of the winter season. Thus, a flexible definition of the term 'cold spell' is required. Generally, a cold spell is defined as the time period during which the minimum daily temperatures are lower than the mean seasonal value and satisfy some particular conditions (Karapiperis 1953, Flocas \& Angouridakis 1979, Zambakas 1981). In this study, a cold spell is defined as the condition at which the daily minimum temperatures fall below a predetermined 'cut-off' level, for a period of at least $1 \mathrm{~d}$.

Extreme temperature events have been studied by many researchers on local, regional and continental scales. Several studies have dealt with the characterisation of cold-spell occurrences in the Mediterranean region and, more generally, in other regions of Europe and the northern hemisphere, e.g. Hop- 


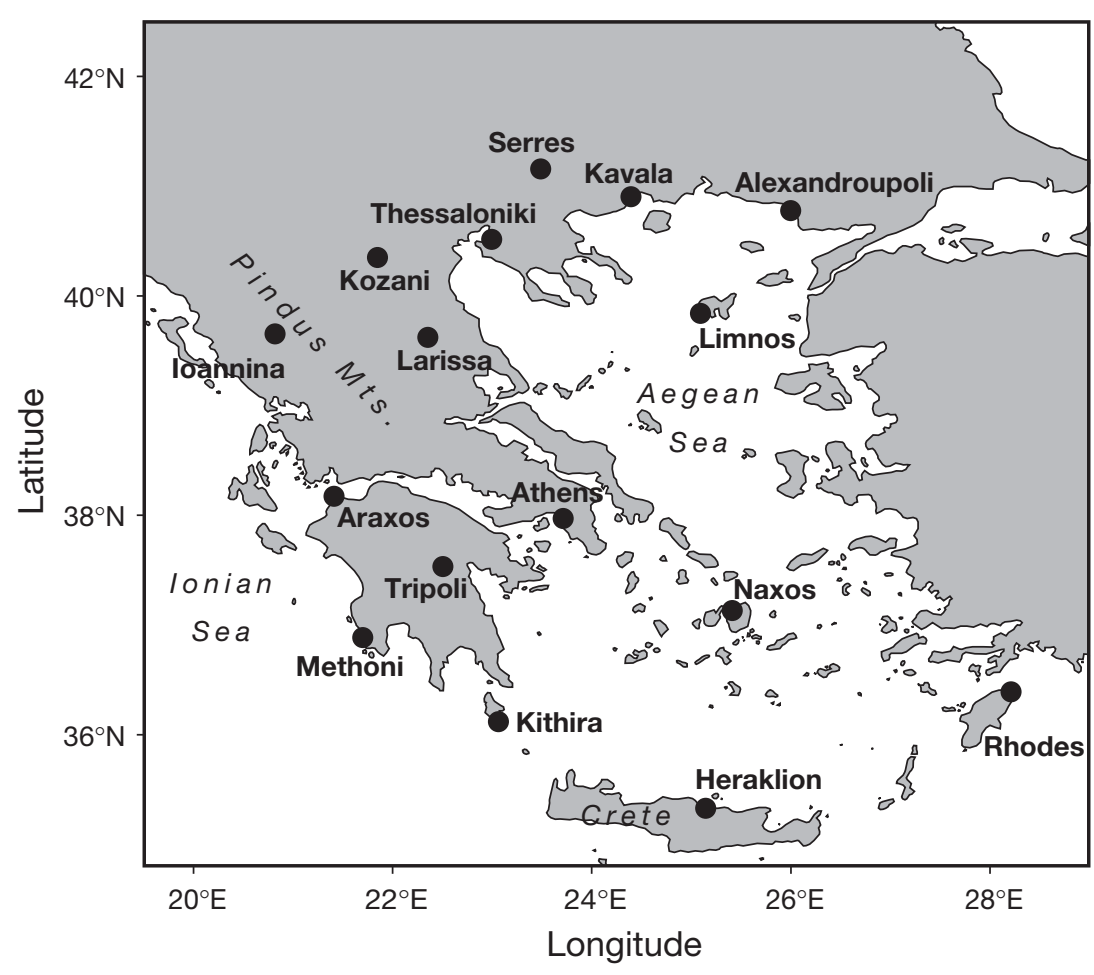

Fig. 1. The broader region for the study of cold spells and the location of stations (see Table 1)

kins \& White (1975), Aprilesi et al. (1977), Brody \& Nestor (1980), Le Boutillier \& Waylen (1988), Waylen \& LeBoutillier (1988), Konrad \& Calucci (1989), Gerstengarbe \& Werner (1992), Macchiato et al. (1993), Lana \& Burgueno (1996), Henderson \& Pittock (1997), Domonkos (1998), and Heino et al. (1999). Studies concerned with extreme temperatures in the Greek region include Karapiperis (1953, 1956a,b), Livadas (1955), Flocas (1970), Repapis (1975), Metaxas (1976), Flocas \& Angouridakis (1979) among others. However, these were based on simple statistical treatment of minimum temperatures, in combination with the analysis of synoptic conditions that caused the cold spells.

This study uses a method introduced by LeBoutillier \& Waylen (1988), applying a combined deterministicstochastic model to study and analyze cold spells. It attempts to determine the period during which they appear, their frequency, spatial and temporal distribution and magnitude (intensity), as well as the synoptic atmospheric conditions that favour their occurrence. The data used in this study cover a $31 \mathrm{yr}$ period. On a local scale, the characteristics of temperature reflect the effects of latitude, longitude, continentality and altitude (Hopkins 1968). For this reason, we attempt here to find a relationship between these variables, as well as the coefficients and parameters of the temperature models.

\section{STUDY REGION AND DATA}

\subsection{Physicogeographical characteristics}

The Greek region (peninsula and islands) has a coverage of about $8^{\circ}$ latitude and $7^{\circ}$ longitude (Fig. 1). Although it belongs mainly to the Mediterranean climatic zone, the region is not a geographical and climatological entity and may be divided into 3 main sections. The Pindus mountains represent the most significant topographic feature that affects the weather in the area. They are located along the peninsula and run from the NW to the SE of the region, parallel to the coast and usually in close proximity to it. These mountains divide the peninsula into 2 entities: the western and eastern sections. A third entity consists of numerous islands, which further complicate the area's topography, and the SE coastal regions of the Aegean Sea and Crete. The climate here is more temperate, owing to the relatively warm sea. In fact, Greece includes many subareas with different physicogeographical and climatic characteristics. According to Köppen's classification, the Mediterranean type Csa is prevalent, but the adjacent types Csb, Cfa, and $\mathrm{Cfb}$ also appear (Zambakas 1981). The whole area has winter mean minimum temperatures within the range of $15^{\circ} \mathrm{C}$ (Karapiperis 1964).

The major orographical factors influencing the Greek climate are the barrier effects of Balkan and Greek mountain ranges (rising above $2000 \mathrm{~m}$ ) and the destabilizing effect of the eastern Mediterranean Sea. The great irregularity of land and water distribution and marked contrasts in topography create a wide variety of deviations from the common climatic pattern of the Mediterranean.

Differences in latitude and in physical characteristics between water, land and snow-covered mountains inland, together with the advection of different air masses, are responsible for the large contrasts in the distribution of temperatures over the region in winter. Thus, for example, the winter along the southern coasts of the Greek peninsula and on the islands is much warmer than along the north Ionian and Aegean sea coasts.

\subsection{Dataset}

Meteorological stations of the Hellenic National Meteorological Service (HNMS), providing complete and reliable data series of daily minimum and maxi- 
mum temperatures, cover the Greek area (Fig. 1). A $31 \mathrm{yr}$ series (1967 to 1997) of daily minimum temperatures are used here from 12 stations, as well as data for different periods of time (16 yr) from 4 stations. Here, daily minimum temperature is defined as the lowest recorded temperature of a day at a station. Unreliable data were excluded from the analysis. Table 1 shows the 16 stations used in this study and the period of available data. For the days and periods of cold spells, synoptic surface maps were also examined-taken from the HNMS and from the daily weather forecast of German Meteorological Service (GMS, Täglicher Wetterbericht) - in order to determine and classify the synoptic conditions that favour the development of cold spells in Greece.

\section{DEFINITIONS AND METHODS}

\subsection{Definitions}

Cold spells during which the individual daily minimum temperatures $T(t)$ are lower by a predetermined value than the expected daily minimum temperature $D(t)$, can be examined by using some specific variables (Fig. 2). The cut-off level $U(t)$, below which the occurrences of daily minimum temperatures indicate the existence of a cold spell, can be defined either in terms of practical aspects or arbitrarily. The times of downcrossings represent the series of the timing of these events, $\tau_{1}, \tau_{2}, \ldots, \tau_{\mathrm{n}}$. Let us suppose that $n(t)=0,1,2, \ldots$ is the number of cold spells for a period up to Day $t$, where $1 \leq t \leq 365$. For each of the $n(t)$ cold spells, there

Table 1. The meteorological stations of the Hellenic National Meteorological Service (HNMS) and the period of data used

\begin{tabular}{|lcccc|}
\hline Station & $\begin{array}{c}\text { Lati- } \\
\text { tude }\end{array}$ & $\begin{array}{c}\text { Longi- } \\
\text { tude }\end{array}$ & $\begin{array}{c}\text { Altitude } \\
(\mathrm{m})\end{array}$ & Years \\
\hline Athens & $37^{\circ} 58^{\prime}$ & $23^{\circ} 44^{\prime}$ & 107 & $1967-1997$ \\
Thessaloniki & $40^{\circ} 31^{\prime}$ & $22^{\circ} 58^{\prime}$ & 20 & $1967-1990$ \\
Ioannina & $39^{\circ} 42^{\prime}$ & $20^{\circ} 49^{\prime}$ & 483 & $1982-1997$ \\
Methoni & $36^{\circ} 50^{\prime}$ & $21^{\circ} 43^{\prime}$ & 33 & $1967-1997$ \\
Araxos & $38^{\circ} 09^{\prime}$ & $21^{\circ} 25^{\prime}$ & 15 & $1967-1997$ \\
Tripoli & $37^{\circ} 32^{\prime}$ & $22^{\circ} 24^{\prime}$ & 652 & $1967-1997$ \\
Kozani & $40^{\circ} 18^{\prime}$ & $21^{\circ} 47^{\prime}$ & 627 & $1967-1997$ \\
Larissa & $39^{\circ} 38^{\prime}$ & $22^{\circ} 25^{\prime}$ & 74 & $1967-1997$ \\
Kavala & $40^{\circ} 59^{\prime}$ & $24^{\circ} 36^{\prime}$ & 5 & $1985-1997$ \\
Alexandroupoli & $40^{\circ} 51^{\prime}$ & $25^{\circ} 55^{\prime}$ & 3 & $1967-1997$ \\
Serres & $41^{\circ} 04^{\prime}$ & $23^{\circ} 34^{\prime}$ & 35 & $1972-1997$ \\
Limnos & $39^{\circ} 55^{\prime}$ & $25^{\circ} 14^{\prime}$ & 4 & $1974-1997$ \\
Rhodes & $36^{\circ} 24^{\prime}$ & $28^{\circ} 05^{\prime}$ & 11 & $1967-1997$ \\
Naxos & $37^{\circ} 06^{\prime}$ & $25^{\circ} 23^{\prime}$ & 9 & $1967-1997$ \\
Heraklion & $35^{\circ} 20^{\prime}$ & $25^{\circ} 11^{\prime}$ & 39 & $1967-1996$ \\
Kithira & $36^{\circ} 17^{\prime}$ & $23^{\circ} 01^{\prime}$ & 167 & $1967-1997$ \\
\hline
\end{tabular}

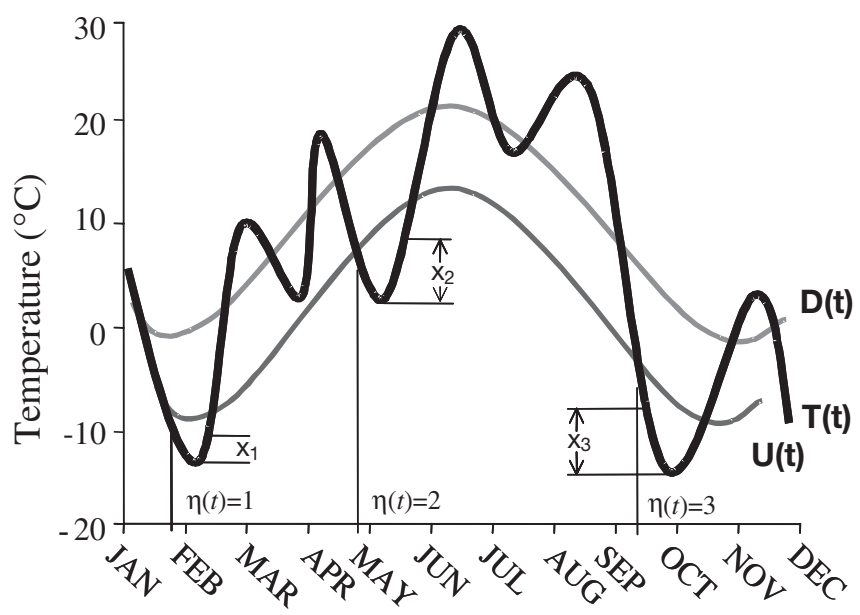

Fig. 2. Hypothetical thermograph of daily minimum temperatures $T(t)$, showing the variables that determine a cold spell. $D(t)$ is the expected long-term minimum daily temperature and $U(t)$ is the cut-off temperature level (as in Fig. 1 of LeBoutillier \& Waylen 1988); $\eta(t)$ is the number and $\mathrm{x}$ is the magnitude of the cold spell

exists a starting date (downcrossing $U(t)$ ) for the cold spell $(\tau)$ and a date when the cold spell ends (upcrossing $U(t), \tau+\Delta t)$, as well as a coldest temperature $(\chi)$ below the predetermined cut-off level. The characteristics of both the expected daily temperatures and the probability of deviations from the normal values have periodic and harmonic variations.

The intensity (magnitude) of a cold spell $(\chi)$ is defined as the maximum absolute difference between $T(t)$ and $U(t)$ during the cold spell, i.e. $\chi_{i}=$ $\max |T(t)-U(t)|$ for $\tau \leq t \leq \tau+\Delta t$ and it gives the series of $\chi_{1}, \chi_{2}, \ldots, \chi_{n}$.

To obtain reliable results, the cut-off level must be selected at a temperature level that ensures the largest number of statistically independent cold spells; the results can be extrapolated also to any other temperature level.

There may be 2 aspects to the establishment of thresholds for cold spells:

(1) Exceeding fixed absolute values. Given that in most Greek areas, temperatures during a cold spell are lower than $0^{\circ} \mathrm{C}$, the fixed value of $0^{\circ} \mathrm{C}$ is one of the applied temperature cut-off levels $U(t)$ on each day $t$.

(2) Deviation from normal. The mean daily minimum temperatures in northern Greek areas are lower than in southern areas. Thus, in order to account for this effect, other truncation levels were also tested. Examination of the number of crossings per year revealed that a new truncation level $U^{\prime}(t)$ of $10^{\circ} \mathrm{C}$ below the mean value yields the maximum number of independent events and yet meets the Poisson assumption of a stochastic process. The results are discussed in Section 4. 


\subsection{Methodology}

The method used in this study (LeBoutillier \& Waylen 1988) consists of a combined deterministic and stochastic model which uses linear regression and Fourier analysis, as well as simple statistical distributions to determine the frequency, spatial distribution, intensity and timing of cold-spell events. More specifically, the technique fulfils the following: (1) it adopts as decisive factors the long-term tendency and the seasonal periodicity of temperature, which can be computed by using linear regression and Fourier analysis, respectively; (2) it analyzes the probability of occurrence of cold spells, by applying simple statistical probability distributions (WMO 1983, Ross 1985); (3) it investigates the extension of the results of a predetermined cut-off level to lower or higher cut-off levels.

It is generally accepted that in extratropical regions the expected measurements of daily temperatures can be approximated to a simple harmonic representation (Rayner 1971, Aprilesi et al. 1977, Neilson \& Hsieh 1982, WMO 1983). In the measurements that compose time series, likely climatic changes can be also detected, the form of which can be complex (Katsoulis 1987). However, the use of a linear approach is often more suitable for detecting and representing possible climatic changes.

The expected daily minimum temperature $D(t)$, at Day $t$ of the year, is given by a simple harmonic relationship as the sum of the annual mean daily minimum temperature and a single harmonic term of the annual cycle:

$$
D(t)=\bar{T}+A \sin [2 \pi t /(365+\varphi)]
$$

where $\bar{T}$ is the annual mean daily minimum temperature, $A$ is half of the annual range of daily minimum temperatures, $\varphi$ is the phase angle and $t$ is the day number (1 to 365) in a calendar year. Any long-term tendency in the annual mean daily minimum temperature is assumed to be linear, so $\bar{T}$ is represented by the equation:

$$
\bar{T}=\mathrm{a}+\mathrm{b} \text { (year) }
$$

where $\mathrm{a}$ and $\mathrm{b}$ are the intercept and the slope, respectively. The small trends revealed by the linear regression, were subsequently removed from daily records and the parameters of the simple harmonic (Eq. 1) were calculated over the detrended record of daily minimum temperature by entering Fourier analysis as:

$$
\begin{gathered}
\varphi=\arctan (\alpha / \beta) \\
A=\sqrt{\alpha^{2}+\beta^{2}} \\
T(t)=A \sin (t R+\varphi)
\end{gathered}
$$

where

$$
R=2 \pi / 365
$$

$$
\begin{aligned}
& \alpha=\frac{2}{365} \sum_{t=1}^{365}\left[\chi_{t} \cos (2 \pi t / 365)\right] \\
& \beta=\frac{2}{365} \sum_{t=1}^{365}\left[\chi_{t} \sin (2 \pi t / 365)\right]
\end{aligned}
$$

The simple harmonic term of Eq. (1) was found to interpret more than $98 \%$ of the fluctuation of all linear detrended series.

The characteristics of cold-spell events are described by 3 variables, the number of occurrences $(n(t))$, the timing $(t)$ and the magnitude $(\chi)$ (Fig. 2). Each of these variables can be approached by theoretical probability distributions, on the basis of crossing theory (Cramer \& Leadbetter 1967).

The number of cold spells $n(t)$ experienced up to Day $t$ of the study time period is given by the nonhomogeneous Poisson distribution:

$$
P(n, t)=\mathrm{e}^{-\lambda(t)} \lambda(t)^{-\mathrm{n}} / \mathrm{n} !, \text { where } \mathrm{n}=0,1, \ldots
$$

The parameter $\lambda(t)$ changes during the time period and its seasonal variability is related to the cumulative relative frequency of cold spells. LeBoutillier \& Waylen (1988) have shown that the Gauss distribution provides a reasonable fit to the $t$-dependence of days of coldspell events and that $\lambda(t)$ can be represented by:

$$
\lambda(t)=\Lambda G(t)
$$

where $\Lambda$ is the mean number of cold spells within the cold period and $G(t)$ is a Gauss distribution given by:

$$
G(\tau \leq t)=\int_{-\infty}^{t} \frac{1}{\sqrt{2 \pi \sigma}} \mathrm{e}^{-(s-\mu)^{2} / 2 \sigma^{2}} d s
$$

where $s$ is the timing of cold spells. The parameters $\mu$ and $\sigma^{2}$ (mean value and the variance of the timing of cold spells) are estimated by the method of moments.

To make easier the estimation of the relative parameters given by Eqs. (3) and (4), 1 December and 31 March are used as the start and end dates of the cold period of the year (29 February is omitted for the leap years).

The distribution of absolute daily minimum temperature in a cold spell, which is lower than the cut-off temperature by $\chi_{1}$ is given by the exponential distribution:

$$
M(X \geq \chi)=\mathrm{e}^{-\chi / \gamma}
$$

where $M$ is the absolute daily minimum temperature in a cold spell, $X$ is the cut-off temperature, $\gamma$ is the mean magnitude of cold-spell events.

\section{STATISTICAL ANALYSIS AND RESULTS}

The application of linear regression to the timeseries of the annual mean minimum temperatures for 

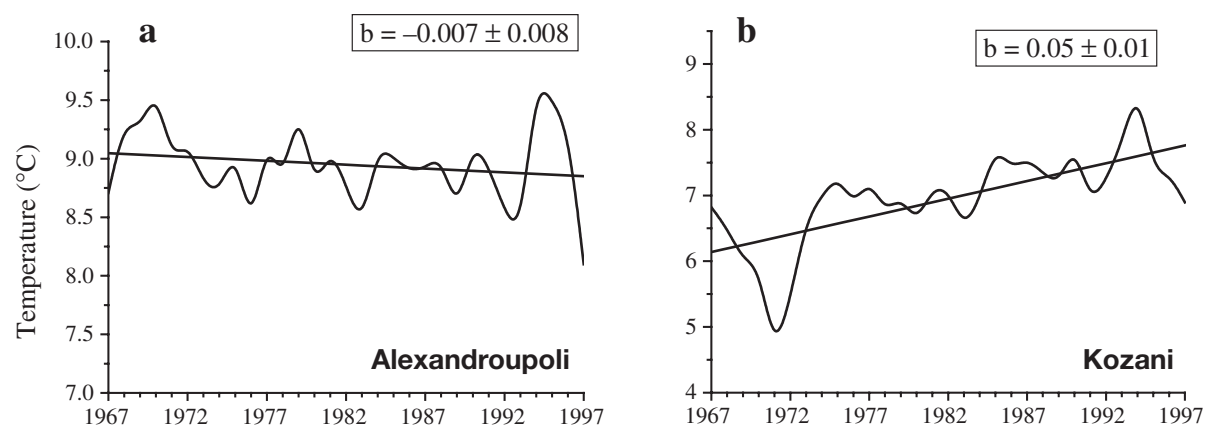

Fig. 3. Time series and linear regression (with slope values b) of the annual mean minimum temperatures for 5 representative stations of the Greek region
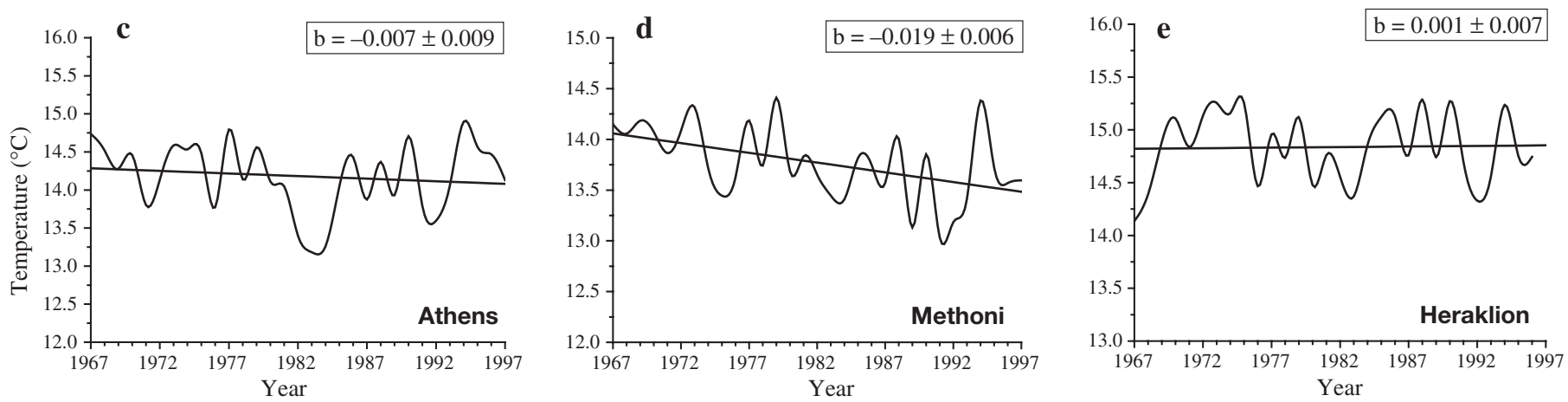

all stations (from 1 December to 31 March) revealed that the slope is different from 0 (at the $95 \%$ level of significance). As an example, computed results are given for 5 stations representative of the Greek region (Fig. 3), showing an apparent increasing trend for the station of Kozani in contrast to a decreasing trend at Methoni, whereas at the stations of Alexandroupoli, Athens and Heraklion there are smaller trends. The obtained trends and tendencies are (more or less) statistically significant at the 95\% level.

The parameters of Fourier analysis are tabulated in Table 2 . The values of $\bar{D}$ vary between about 7 and $15.5^{\circ} \mathrm{C}$. The lowest value for Kozani is due to its inland location (altitude $627 \mathrm{~m}$, cf. Table 1). The highest value of $15.55^{\circ} \mathrm{C}$ at Heraklion is due to the fact that this station is located on Crete. In general, mean annual daily minimum temperatures are higher at southern than at northern Greek stations. The spread in the computed $\bar{D}$ values is about $8.5^{\circ} \mathrm{C}$. The semi-amplitude $(A)$ ranges between 7.2 and $9.2^{\circ} \mathrm{C}$, whereas the phase-angle $\varphi$, ranges from 0.9 to 1.13 (Table 2). Note the lower annual range of daily minimum temperature in southern and SE stations (Heraklion, Methoni and Athens) compared to northern ones, which is partly due to the influence of the sea. As far as it concerns $\varphi$ (which is related to the seasonality, the calendar date on which the cold-spell events are expected), the SE and southern stations (Athens and Methoni) are characterised by earlier events than the northern ones (Kozani and Alexandroupoli).
Fig. 4 shows the fluctuations of observed and expected daily minimum temperatures, $T(t)$ and $D(t)$, respectively, and the temperature cut-off level $(U(t))$ from 1 January to 30 March for 1991 (1991 was chosen as an example). The same procedure was applied to each station for each year. The cold spells for the study period were derived from $T(t)$ and $U(t)$. Fig. 4 also shows the modified cut-off levels $\left(U^{\prime}(t)\right)$ derived by subtracting $10^{\circ} \mathrm{C}$ from $D(t)$ (as explained in section 3.2). This alternative leads to higher temperature cutoff levels $U^{\prime}(t)$ than $U(t)$ for the southern stations of Athens, Methoni, and Heraklion, and produces more cold spells. In contrast, the cut-off levels $U^{\prime}(t)$ are lower than $U(t)$ for the northern stations of Alexandroupoli and Kozani, resulting in fewer cold spells. The larger number of cold spells obtained by using $U^{\prime}(t)$ may be considered more realistic than that obtained with the cut-off level $U(t)$. Nevertheless, the selection of $U(t)$ instead of $U^{\prime}(t)$ maximizes the effectiveness of coldspell events. The overall results obtained revealed that

Table 2. Values of half width range A, phase angle $\varphi$, and annual mean expected daily minimum temperatures $\bar{D}$ (Eq. 1) at 5 representative Greek stations

\begin{tabular}{|lccc|}
\hline Stations & A & $\varphi$ & $\bar{D}$ \\
\hline Alexandroupoli & 8.957 & 1.129 & 9.102 \\
Kozani & 9.240 & 1.106 & 7.147 \\
Athens & 8.331 & 0.968 & 14.570 \\
Methoni & 7.529 & 0.905 & 14.261 \\
Heraklion & 7.208 & 0.906 & 15.551 \\
\hline
\end{tabular}



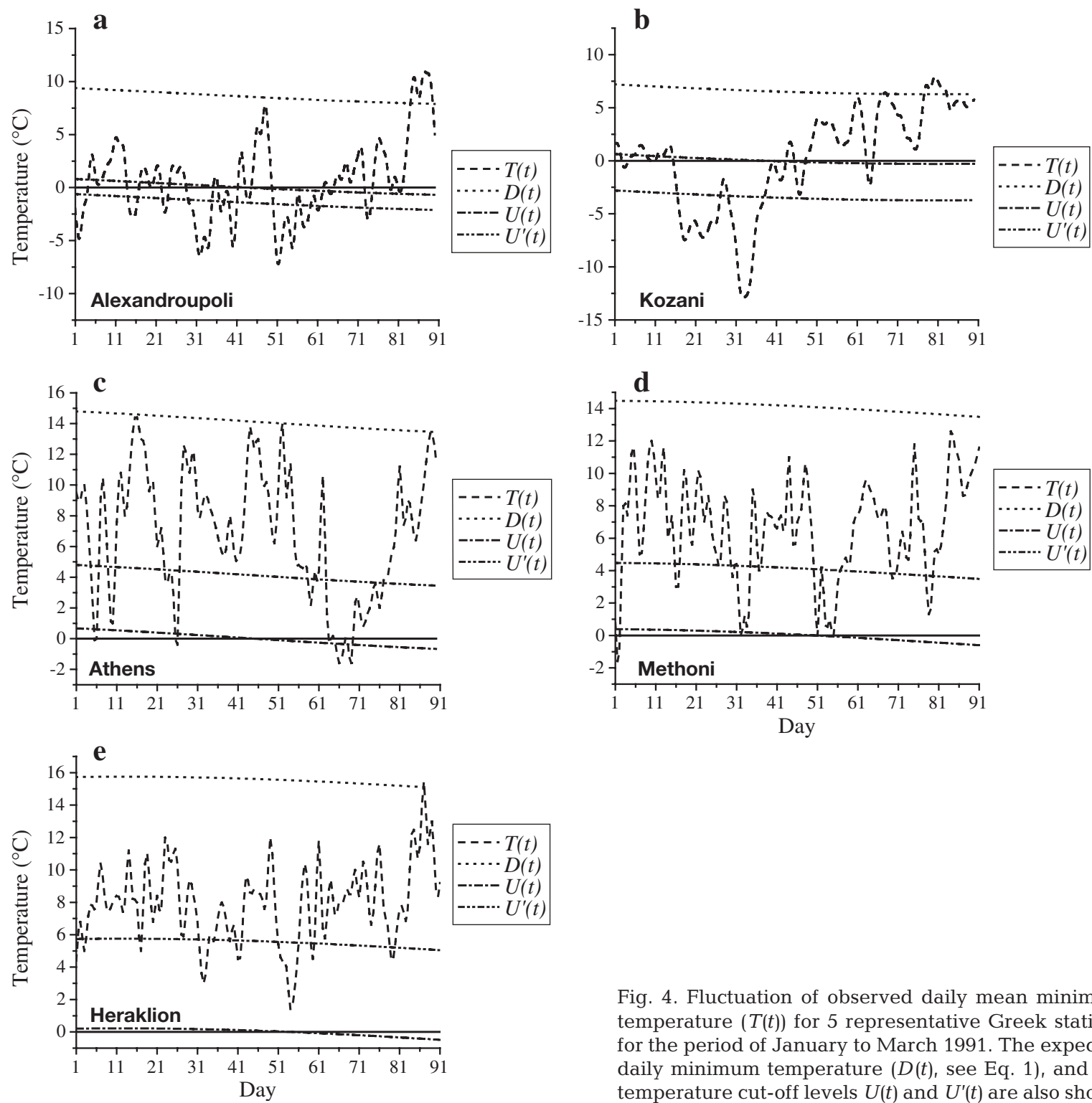

Fig. 4. Fluctuation of observed daily mean minimum temperature $(T(t))$ for 5 representative Greek stations for the period of January to March 1991. The expected daily minimum temperature $(D(t)$, see Eq. 1$)$, and the temperature cut-off levels $U(t)$ and $U^{\prime}(t)$ are also shown

in northern Greek areas cold-spell events occur mainly from the beginning of January to mid-February, while in southern areas cold spells are seldom observed; most of the few events occur around late February and early March.

The recorded number of cold spells per year was fitted and examined by applying the Poisson distribution (Eq. 9), since it represents rare random events (Fig. 5). The plots show the observed and theoretical Poisson distributions, together with $\Lambda$ (the computed mean number of cold spells), for the 5 selected Greek stations. Fig. 5 also shows the results obtained by using both temperature cut-off levels $U^{\prime}(t)$ and $U(t)$. There is good agreement between the observed and theoretical distributions, both showing a gradual decrease from north to south in the probability of cold spells. When

the cut-off level $U(t)$ is used, the probability of cold spells ranges from about 11 spells for the northern locations to 0 spells or only 1 spell for the southern ones. The low number ( 0 to 1 event) of cold spells at southern stations obtained by using the cut-off level $U(t)$, results from the fact that $U(t)$ is equal to about $0^{\circ} \mathrm{C}$ for all Greek stations in this case. Thus, the higher minimum temperatures in southern Greece lead to fewer cold spells in southern areas than in northern areas. However, using the cut-off level $U^{\prime}(t)$, the number of cold spells increases to about 3 to 7 events at the southern stations (Fig. 5h-j). In contrast, the probability of cold spells decreases from about 11 to 9.7 and 7.2 cold spells in the northern stations (Fig. $5 \mathrm{f}-\mathrm{g}$ ).

The $\chi^{2}$ goodness-of-fit test provides good agreement between the theoretical and real distributions, both 

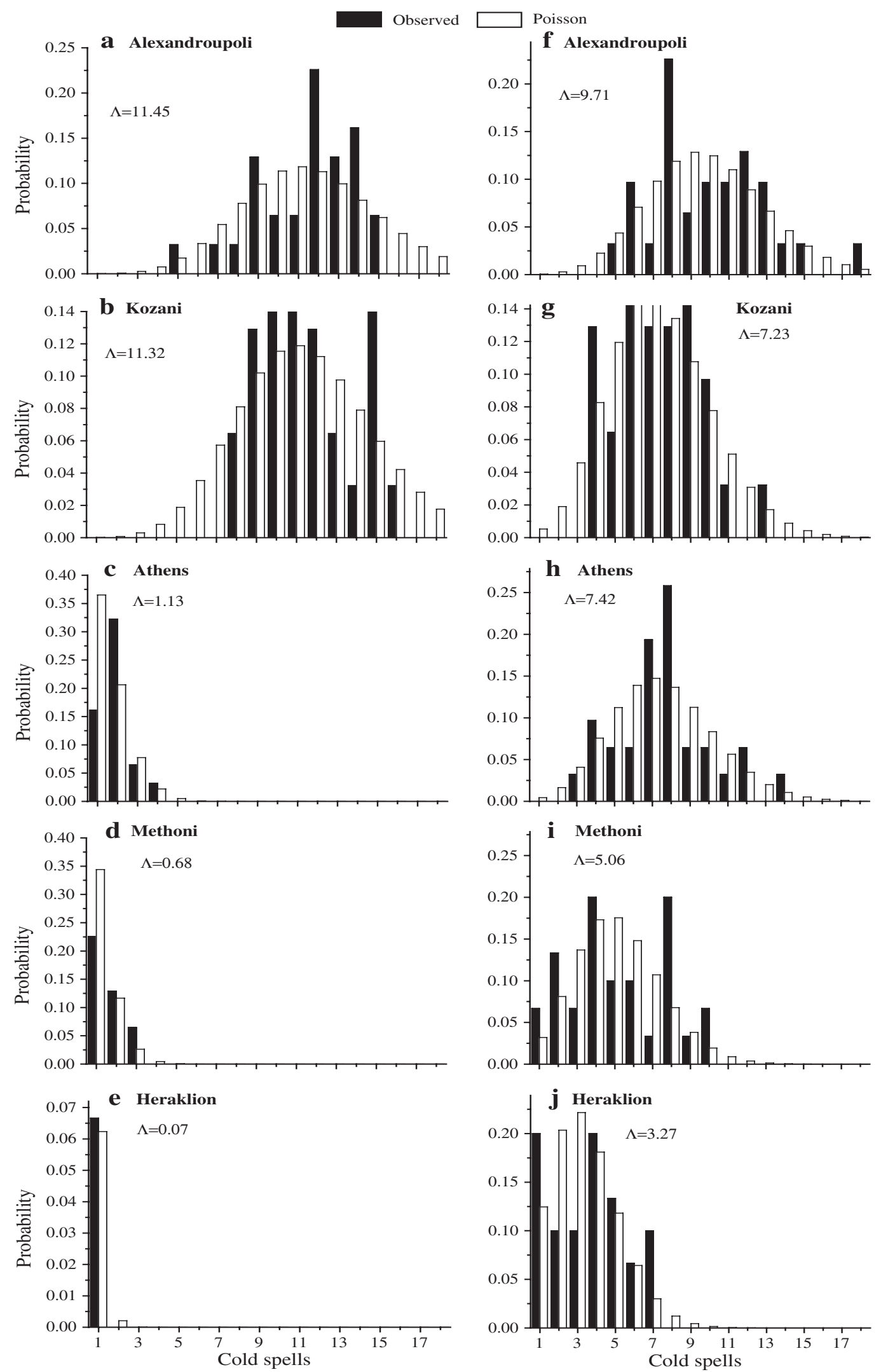

Fig. 5. (a-e) Probability distribution of the observed number of cold spells and the corresponding theoretical Poisson distribution by using temperature cut-off level $U(t)$. (f-j) Corresponding distributions computed by using the cut-off level $U^{\prime}(t)$ instead of $U(t)$. $\Lambda$ is the mean number of cold spells from the Poisson distribution 
showing a gradual north-to-south decrease in the probability of occurrence of cold spells per year.

Fig. 6 gives the probability of timing of cold spells observed and computed with the cumulative Gauss distribution (Eq. 11) and the values of parameters $\mu$ and $\sigma^{2}$. In all cases, the Gauss distribution provides a satisfactory fit to the observed timing of cold spells. The largest deviations are found for the stations of Athens and Methoni, which are characterized by fewer occurrences of cold spells. Note that the Gauss distribution provides a better fit to the real timing of cold spells when the cutoff level $U^{\prime}(t)$ is used, since it involves more occurrences of cold-spell events. Note also that for the Heraklion station the Gauss distribution of timing of cold spells is not possible when using the cut-off level $U(t)$ because of the very low cold-spell frequencies (Fig. 5e); however, this becomes possible by choosing $U^{\prime}(t)$. In general, the theoretical Gauss distribution shows good agreement to a large extent (at the $95 \%$ significance level), with the observed timing of cold spells. The mean timing varies around the period 28 January to 5 February when using $U(t)$, while it varies from 30 January to 7 February when using the cut-off level $U^{\prime}(t)$, with SD equal to 4 to $5 \mathrm{~d}$ in both cases.

The mean intensity of cold spells was estimated by using the exponential distribution (Eq. 12). The results of our analysis for the 5 selected stations are shown in Fig. 7, where the distribution of the observed magnitude of cold spells is compared with the corresponding fitted exponential distribution. In general, the exponential distribution provides good agreement with the distribution of magnitude of cold-spell events. Fig. 7 also gives the parameter $\gamma$ (Eq. 12); the value of $\gamma$ ranges from about 1 to $3^{\circ} \mathrm{C}$, depending on the station and the cut-off level adopted. No results are given at the Heraklion station for level $U(t)$ because of the extremely low frequency of cold spells there. The use of cut-off level $U^{\prime}(t)$ makes it possible to obtain results. In general, a slightly better fit is obtained when using the cut-off level $U^{\prime}(t)$ instead of $U(t)$. The mean magnitude of cold spells computed with $U^{\prime}(t)$ is slightly smaller (by 0.4 to $0.8^{\circ} \mathrm{C}$ ) than that computed with $U(t)$ in the northern stations, while it is slightly larger (by $0.8^{\circ} \mathrm{C}$ ) in the southern stations. The $\chi^{2}$-test for the applied theoretical exponential distribution reveals agreement (95\% significance level).

Table 3 , shows the mean values of frequency $(\Lambda)$, timing $(\mu)$ and associated variance $\left(\sigma^{2}\right)$ and magnitude $(\gamma)$ of cold-spell events for the 16 Greek stations, computed with the theoretical distributions. Also shown are the values computed by using the cut-off level $U^{\prime}(t)$. Absence of $\mu, \sigma^{2}$ and $\gamma$ values (for $U(t)$ ) for the stations of Naxos and Heraklion are due to the very low frequencies of cold spells there ( 0.1 and 0.07 , respectively). The frequency generally increases with latitude and altitude. Thus, the highest cold-spell frequencies $(>10)$ are found at stations of central and, particularly, northern Greece, as well as at high-altitude stations located in the Pindos and Peloponnese mountain ranges. Geographical latitude and altitude are the most important parameters determining the frequency of cold spells in Greece. Continentality also affects the frequency of cold spells; thus, some coastal stations have lower frequencies of cold spells (e.g. Kavala, about 10 events) than other continental stations with similar latitude (e.g. Serres, about 12 events). However, it is difficult to clarify the role of continentality in determining the frequency of cold spells because the latter is also affected, to a large extent, by the prevailing synoptic situation (see next section). In general, the strongest cold spells are found at stations which are also characterized by highest frequencies. Nevertheless, whereas the highest frequency (14.7 events) is found at Tripoli station, followed by Ioannina (13.2) and Larissa (12.2), the strongest cold-spell events are found at Kozani $\left(3.3^{\circ} \mathrm{C}\right)$, followed by Alexandroupoli, Ioannina and Thessaloniki $\left(\sim 3^{\circ} \mathrm{C}\right)$. Therefore, it appears that latitude and altitude are the most important factors that determine the intensity of cold-spell events.

The isopleths of the number of cold spells per year, for the Greek region, are given in Fig. 8. The frequency of cold spells increases with latitude, as expected. There are more cold spells in western and northern Greece. This is consistent with the classifica-

Table 3. Values of computed mean number $(\Lambda)$, mean timing $(\mu)$, variance of mean timing $\left(\sigma^{2}\right)$ and mean magnitude $\left(\gamma\right.$, in $\left.{ }^{\circ} \mathrm{C}\right)$ of cold-spell events at 16 stations of the Hellenic National Meteorological Service (HNMS). The values in parenthesis are computed by using temperature cut-off level $U^{\prime}(t)$ instead of $U(t)$

\begin{tabular}{|lclll|}
\hline Stations & \multicolumn{1}{c}{$\Lambda$} & \multicolumn{1}{c}{$\mu$} & \multicolumn{1}{c}{$\sigma^{2}$} & \multicolumn{1}{c|}{$\gamma$} \\
\hline Athens & $1.13(7.42)$ & $28.26(32.2)$ & $20.32(20.56)$ & $1.12(1.76)$ \\
Thessaloniki & 10.88 & 30.39 & 20.67 & 3.02 \\
Ioannina & $13.25(9.06)$ & $34.74(32.4)$ & $22.16(20.23)$ & $3.02(2.16)$ \\
Methoni & $0.68(5.06)$ & $30.30(37.7)$ & $21.08(22.20)$ & $0.98(1.78)$ \\
Araxos & 2.65 & 30.23 & 20.24 & 1.23 \\
Tripoli & 14.68 & 38.46 & 23.40 & 2.78 \\
Kozani & $11.32(7.23)$ & $32.63(30.3)$ & $22.39(20.76)$ & $3.29(2.78)$ \\
Larissa & 12.23 & 33.23 & 21.98 & 2.98 \\
Kavala & 9.88 & 33.06 & 20.34 & 2.39 \\
Alexandroupoli & $11.45(9.71)$ & $33.50(31.4)$ & $21.57(20.14)$ & $3.05(2.75)$ \\
Serres & 11.88 & 33.06 & 20.34 & 2.87 \\
Limnos & 6.50 & 31.83 & 20.29 & 1.44 \\
Rhodes & 0.19 & 26.67 & 12.63 & 1.39 \\
Naxos & 0.10 & - & - & 1.11 \\
Heraklion & $0.07(3.27)$ & $-(38.4)$ & $-(20.78)$ & $-(1.34)$ \\
Kithira & 0.26 & 30.31 & 21.08 & 0.87 \\
\hline
\end{tabular}



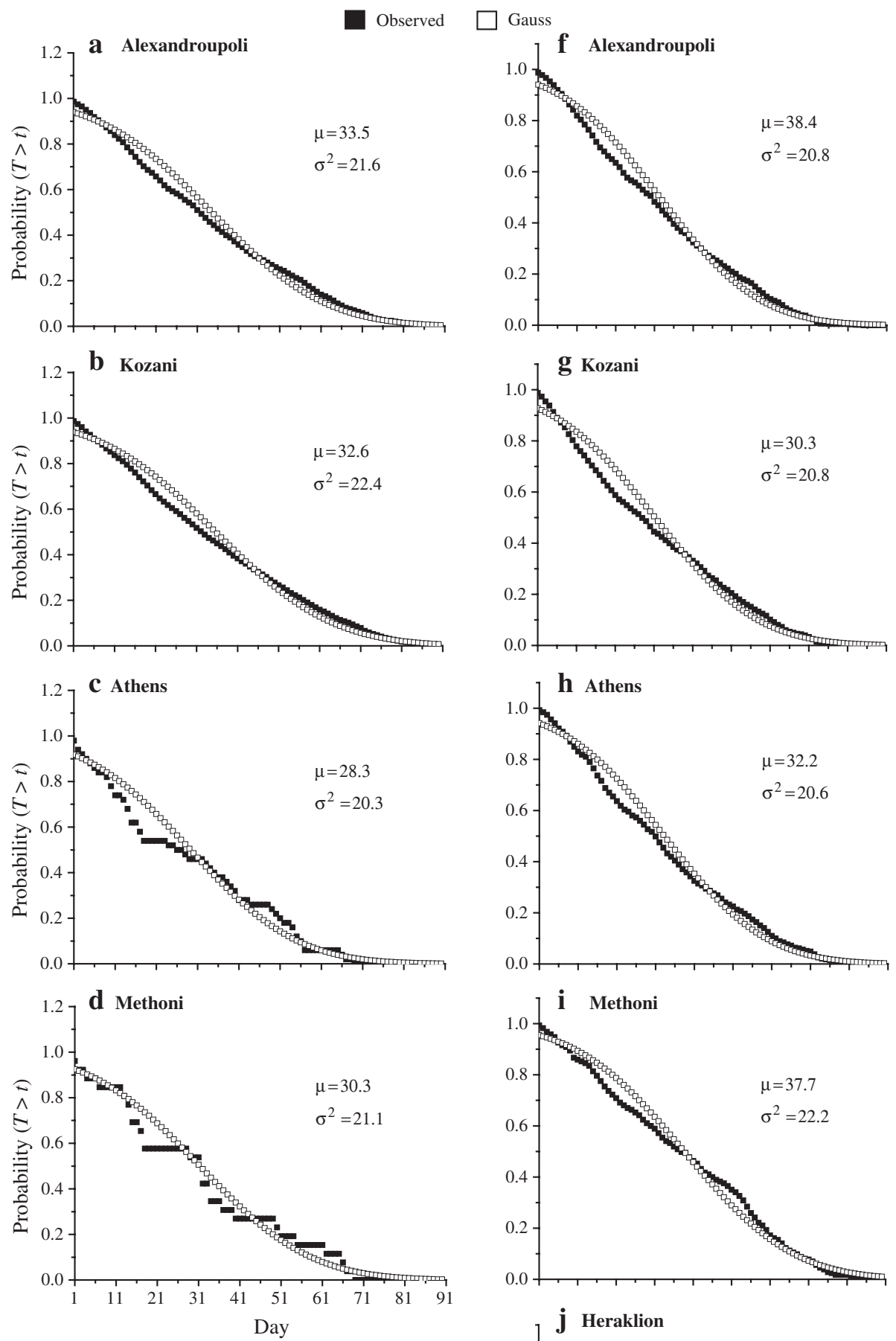

e (no data)

Fig. 6. Observed and fitted cumulative Gauss probability distributions of the timing of cold spells at the 5 representative Greek stations. Left and right columns as in Fig 5 (no result is given for Heraklion for level $U(t)$ because of the low frequency of cold spells there). The mean timing of cold spells $(\mu)$ and the variance $\left(\sigma^{2}\right)$ are also given

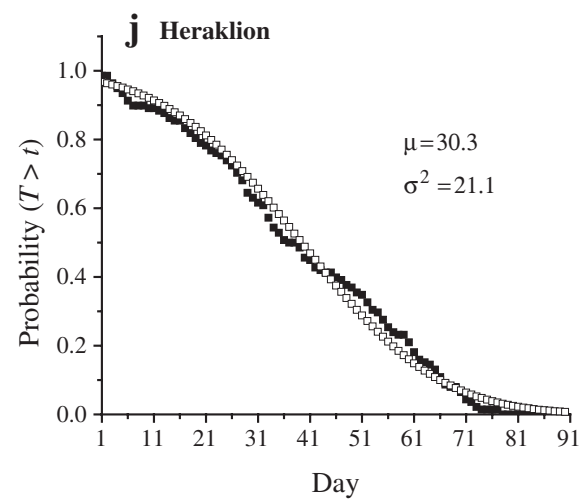



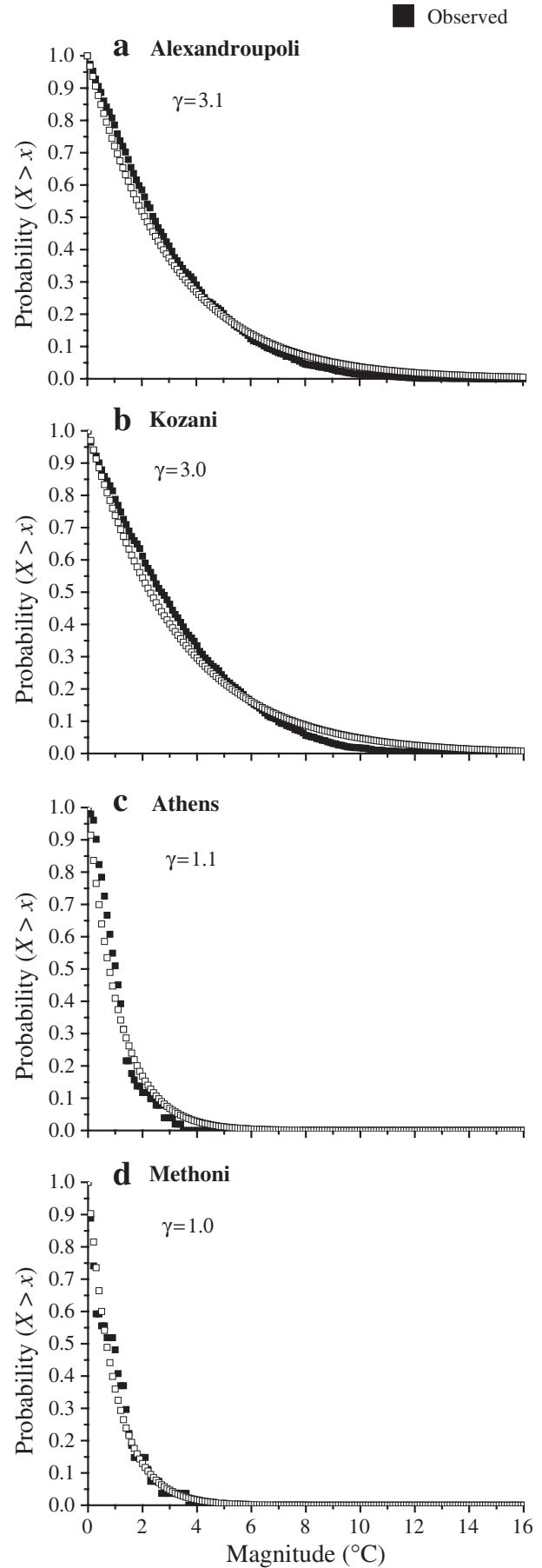

e (no data)

Fig. 7. Probability distribution of the observed magnitude of cold spells and the corresponding fitting exponential distribution at the 5 representative Greek stations. Left and right columns as in Fig. 5 (no result is given for Heraklion for level $U(t)$ because of the low frequency of cold spells there). The value of the mean magnitude of cold spells $(\gamma)$ is also given
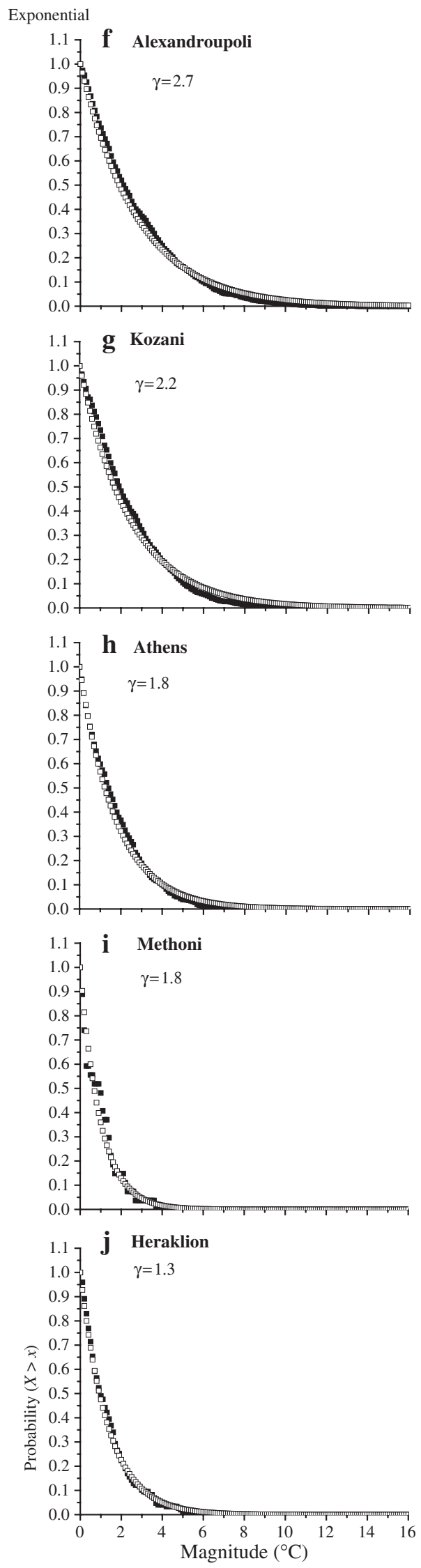


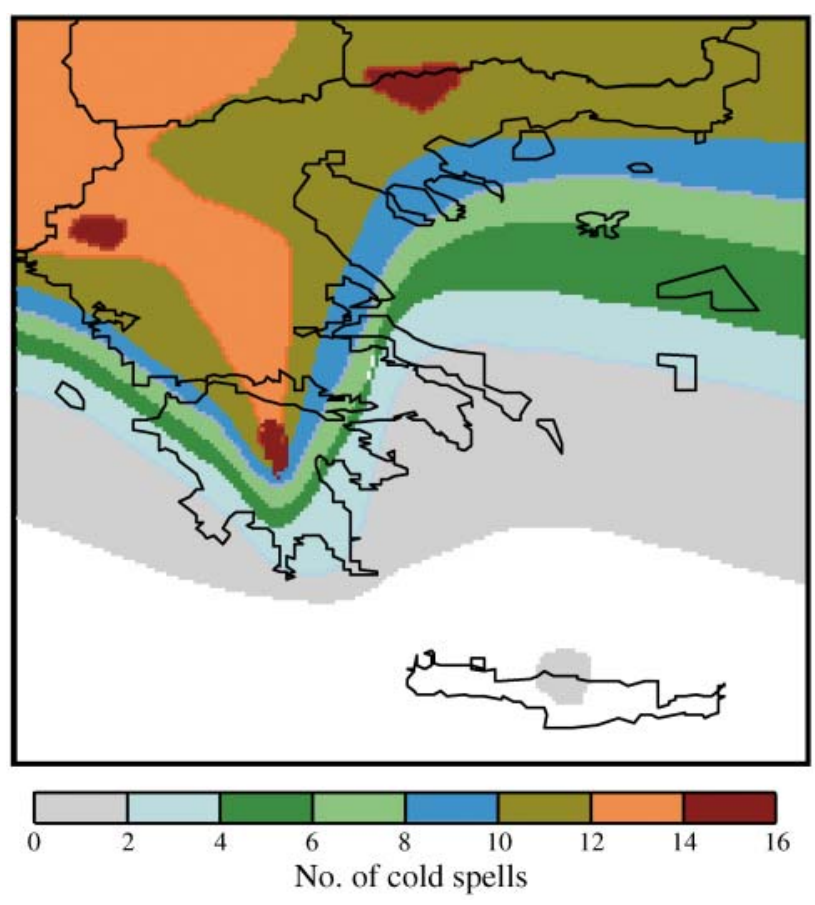

Fig. 8. Isopleths of the number of cold spells per year in the Greek region

tion of weather synoptic situations over Greece (see Section 5). For the interpretation of the features in Fig. 8, it is also important to take into account the altitude of the stations (see Table 1).

Subsequently, the role of parameters such as geographic latitude, longitude and altitude with respect to the features of cold spells was investigated by applying linear regression analysis (Table 4) at a significance level of $97.5 \%$. The mean number of cold spells is most strongly correlated with latitude $(\mathrm{R}=0.78)$ and secondarily correlated with altitude $(\mathrm{R}=0.52)$. The frequency of cold spells is weakly and negatively correlated with longitude $(\mathrm{R}=-0.38)$. The mean timing of cold spells is significantly less correlated with latitude and longitude $(R \sim \pm 0.4)$ than with altitude $(R=0.68)$, whereas the mean magnitude of cold spells is primarily correlated with latitude $(\mathrm{R}=0.77)$ and secondarily correlated with altitude $(\mathrm{R}=0.48)$. Overall, according to the model results, the features of cold spells are primarily correlated with latitude and secondarily correlated with altitude. In contrast, much weaker correlation was found between longitude and the computed mean features of cold-spell events.

\section{SYNOPTIC CONDITIONS OF COLD-SPELL EVENTS}

The air flow over the Greek region is mainly influenced by (1) the Eurasiatic (Siberian) anticyclone (the circulation of which causes polar continental air to flow from eastern Europe), (2) an anticyclone developing over middle and eastern Europe, and (3) the lowpressure systems in the central Mediterranean. With the upper level westerlies, which are often found over the region, cyclonic activity with unsettled weather is common.

The cold-spell events occurring in the Greek region are strongly affected by, and related to, the synoptic conditions prevailing during their occurrence. Thus, a statistical analysis was performed to investigate the relationship between cold spells, and the associated synoptic conditions which favour their development. Our analysis was performed by using daily (12:00 h UTC) surface and upper-level weather charts, taken from the HNMS and the GMS, during spells of consecutive cold days (with minimum temperatures $\leq 0^{\circ} \mathrm{C}$ ). Our analysis resulted in a classification of the synoptic situations that prevail during cold-spell events, which includes the following 4 categories (A, B, C, D):

(A) The anticyclones of NW and north-central Europe move and extend southwards during winter, transporting cold airmasses that cause abrupt fall in temperatures in southern and SE regions of Europe, Greece included. The velocity of transport of these air masses is higher when these synoptic systems are combined with the presence or the extension of a depression in the eastern Mediterranean area.

(B) The high-pressure systems of central and SW Europe are associated with a secondary high-pressure system in the southern and SE regions of Europe, particularly in the Balkans. In this case, the cold spells appear with high frequency and intensity, which is intensified by the presence of low pressure in the eastern Mediterranean.

Table 4. Computed values of intercept (a), slope (b), correlation coefficient (R) and standard deviation of the fit (SD) for the linear regression between the mean number $(\Lambda)$, mean timing $(\mu)$ and mean magnitude $(\gamma)$ of cold-spell events at 16 stations of the Hellenic National Meteorological Service (HNMS) and the associated latitude, longitude and altitude

\begin{tabular}{|cccccc|}
\hline & & $\mathrm{a}$ & $\mathrm{b}$ & $\mathrm{R}$ & $\mathrm{SD}$ \\
\hline$\Lambda$ & Latitude & -83.31 & 2.34 & 0.78 & 3.47 \\
& Longitude & 32.08 & -1.08 & -0.38 & 5.47 \\
& Altitude & 5.32 & 0.01 & 0.52 & 5.01 \\
$\mu$ & Latitude & 4.23 & 0.72 & 0.42 & 2.82 \\
& Longitude & 46.07 & -0.63 & -0.43 & 2.81 \\
& Altitude & 30.81 & 0.01 & 0.68 & 2.35 \\
$\gamma$ & Latitude & -13.96 & 0.42 & 0.77 & 0.62 \\
& Longitude & 4.92 & -0.12 & -0.26 & 0.94 \\
& Altitude & 1.91 & 0.002 & 0.48 & 0.83 \\
\hline
\end{tabular}


(C) The Eurasiatic anticyclone extends to central and SE Europe, as well as to the Balkan Peninsula. This extension favours the invasion of cold airmasses into Greece, particularly in the northern and NE regions, and into the Aegean Sea. Sometimes, the Eurasiatic anticyclone and that of central Europe, create local high-pressure systems over the Balkans, intensifying the invasion of cold airmasses towards Greece (Maheras et al. 2000).

(D) Cold and stagnant fronts of depressions prevail, moving usually from west to east and crossing the Balkans and the Greek peninsula (Katsoulis 1982).

The frequency of cold spells by category was: (A) $11.6 \%$; (B) $25.5 \%$; (C) $44.9 \%$; (D) $18.0 \%$. Cold spells associated with Category A usually had a short duration.

The results of our classification analysis attribute the cold spells occurring in Greece, primarily, to fronts approaching the region from the north and, secondarily, to high-pressure systems in southern and SE Europe, particularly in the Balkans, as extensions of the anticyclones of central Europe. At the same time, the katabatic cold winds of the western Balkans are intensified by the sloped ground surface, accelerating the cold air masses and increasing the probability of cold spells in western Greece (Meteorological Office 1962). These strong cold downslope winds extend up to the Ionian Islands and the continental areas along the western coast of Greece (Katsoulis 1974, Brody \& Nestor 1980). Their source is so cold that when the air reaches the coast, the dynamic warming is insufficient to raise the air temperature to the normal level for the area. These conditions usually occur during winter after an intense cyclone has moved eastwards across the Ionian Sea. The classification of synoptic weather situations prevailing over Greece during cold-spell events is consistent with the results of Table 3, which indicate generally more events at northern and NW Greek stations than at southern and SE stations.

\section{SUMMARY AND CONCLUSIONS}

In this study, an analysis of the characteristics of coldspell events that occur over Greece was performed by applying a combined deterministic-stochastic model, consisting of the application of theoretical statistical distributions, which maximises the effectiveness of the results. The spatio-temporal characteristics of cold spells were described by utilizing a complete data set, fitted and represented with theoretical distributions. The computed results show:

(1) The application of linear regression to the time series of daily minimum temperatures has revealed small statistically significant trends and tendencies.
(2) The model computed mean annual daily minimum temperatures agree with the measured ones (to within $1^{\circ} \mathrm{C}$ ).

(3) The cold spells in northern Greece occur mainly from the beginning of January to mid-February, while in southern Greece cold spells are seldom observed. When they do occur, it is usually around the end of February and the beginning of March.

(4) There is good agreement between observed and theoretical statistical distributions, both showing a gradual north-to-south decrease in the probability of occurrence of cold-spell events. The frequency varies between 11 and 13 spells for northern Greek regions and 0 spells or only 1 spell in areas south of Athens. However, the frequency of cold spells is strongly dependent on the method of defining the cut-off temperature level $U(t)$.

(5) The Gauss distribution provides a satisfactory fit to the real timing of cold spells. The earliest cold spells occur in the first $10 \mathrm{~d}$ of December, while the latest ones occur by mid-March. In general, the mean timing ranges between about 28 January and 7 February, with an SD of about $5 \mathrm{~d}$.

(6) The exponential distribution provides a good fit to the observed intensity of cold-spell events, with values ranging from 0.87 to $3.3^{\circ} \mathrm{C}$ for southern and northern Greek stations, respectively.

(7) The spatial and temporal distribution of cold spells, as well as their features, depend strongly on latitude, longitude, altitude and continentality. The frequency and intensity of cold spells are primarily correlated with latitude $(\mathrm{R}=0.78)$, while the timing is primarily correlated with altitude $(\mathrm{R}=0.68)$.

(8) The features of cold spells are closely related to the synoptic characteristics of Greek sub-areas (northern, southern, eastern, and southern-island regions). The highest probability for occurrence exists when a persistent north European and/or Eurasiatic (Siberian) anticyclone reaches its highest intensity during winter and extends high-pressure ridges to the Greek area.

In conclusion, the use of such a model to study and analyze the features of cold-spell events in Greece provides a satisfactory fit to the corresponding observed features and reveals many important characteristics. Apart from indicating the significant role of physicogeographical parameters, it also reveals the connection between these parameters and the long-range atmospheric circulation that favours the occurrence of cold spells in the Greek region. The deviation of a cold-spell behavior from this ascertainment is also strongly related to the orientation and downslope of surface terrain. The method applied here can also be used to estimate the characteristics of cold spells for regions in which routine temperature measurements do not exist. 
Acknowledgements. The authors are grateful to the Hellenic National Meteorological Service for kindly providing the available temperature data. They also express their thanks to the anonymous referees for their valuable comments.

\section{LITERATURE CITED}

Aprilesi G, Marsequerra M, Morelli S, Rivasi MR, Saltini G, Santangelo R (1977) Stochastic behaviour of the daily minimum, mean and maximum temperature in Modena, Italy. Mon Weather Rev 105:1434-1441

Barry RG, Perry AH, (1973) Synoptic climatology. Methuen, London

Brody LR, Nestor MJR (1980) Handbook for forecasters in the Mediterranean, Part 2. Naval Env Prediction Research Facility. US Dept of Commerce, Monterey

Cramer H, Leadbetter MR (1967) Stationary and related stochastic processes. John Wiley, New York

Domonkos P (1998) Statistical characteristics of extreme temperature anomaly groups in Hungary. Theor Appl Climatol 59:165-179

Flocas AA (1970) Contribution to the study of hot invasions in Greece. PhD thesis, Aristotelian University, Thessalonica

Flocas AA, Angouridakis VE (1979) Extreme value analysis of air temperature over Greece. Arch Meteorol Geophys Bioklimatol Ser B 27:47-57

Gerstengarbe FW, Werner FN (1992) The time structure of extreme summers in Central Europe between 1901 and 1980. Meteorol Z 1:285-289

Heino R, Bradzil R, Forland E, Tuomenvirta $H$ and 7 others (1999) Progress in the study of climate extremes in northern and central Europe. Clim Change 42:151-181

Henderson KJ, Pittock AB (1997) Extreme temperature days in the south-central United States. Clim Res 8:151-162

Hopkins JW (1968) Correlation of air temperature normals for the Canadian Great Plains with latitude, longitude and altitude. Can J Earth Sci 5:199-210

Hopkins JS, White KW (1975) Extreme temperatures over the United Kingdom for design purposes. Meteor Mag 104: 94-102

IPCC (2001) Climate change 2001: impacts, adaptation, and vulnerability. McCarthy JJ, Canziani OF, Leary NA, Dokken DJ, White KS (eds). Cambridge University Press, New York

Karapiperis L (1953) On the spells of cold weather over the East Mediterranean during the autumn. Arch Meteorol Geophys Bioklimatol Ser B 4:420-430

Karapiperis L (1956a) On the spells of cold weather over the East Mediterranean during the spring. Publ Met Inst Univ Athens, No 4. University of Athens

Karapiperis L (1956b) On the great and abrupt falls of air temperature in Athens. Geofis Pura Appl 35:143-148

Karapiperis L (1964) The climate of Greece. National Observatory of Athens

Katsoulis BD (1974) Contribution to the study of katabatic winds of the western Balkans. Memoirs of the National Observatory of Athens, No 37

Editorial responsibility: Helmut Mayer, Freiburg, Germany
Katsoulis BD (1982) Climatic and synoptic considerations of the Mediterranean depressions developing and passing over or near the Balkan peninsula. Proc 1st HellenicBritish Clim Congr, Athens, Sep 1980. Hellenic Meteorological Society, Athens, p 73-84

Katsoulis BD (1987) Indications of change of climate from the analysis of air temperature time series in Athens, Greece. Clim Change 10:67-79

Konrad CE, Calucci SJ (1989) An examination of extreme cold outbreaks over eastern North America. Mon Weather Rev 117:2687-2700

Lana X, Burgueno A (1996) Extreme winter minimum temperatures in Catalonia (North-east Spain): expected values and their spatial distribution. Int J Climatol 16:1365-1378

Landsberg HE (1977) World survey of climatology, Vol 6. Climates of central and southern Europe. Elsevier, Amsterdam, p 185-223

LeBoutillier DW, Waylen PR (1988) Stochastic analysis of cold spells. J Clim Appl Meteorol 27:67-76

Livadas GK (1955) On the weather conditions during groupdays of abrupt temperature fall. $\mathrm{PhD}$ thesis, Aristotelian University, Thessaloniki

Macchiato M, Serio C, Lapenna V, La Rotonda L (1993) Parametric time series analysis of cold and hot spells in daily temperature: an application in Southern Italy. J Appl Meteor 32:1270-1281

Maheras P, Patrikas I, Karacostas T, Anagnostopoulou C (2000) Automatic classification of circulation types in Greece: methodology, description, frequency, variability and trend analysis. Theor Appl Climatol 67:205-223

Metaxas D (1976) Powerful cold invasions in the Aegean in winter. Bull Hell Meteor Soc 1: 3, 1-11

Meteorological Office (1962) Weather in the Mediterranean. HMSO, London

Neilson BJ, Hsieh BB (1982) Analysis of water temperature records using a deterministic stochastic model. In: ElShaarawi AE, Esterby SR (eds) Developments in water science, vol 17, Time series methods in hydrosciences. Elsevier, msterdam, p 465-473

Plummer N, Salinger MJ, Nicholls N, Suppiah R, Hennessy KJ, Leighton RM, Trewin B, Page CM, Lough JM (1999) Changes in climate extremes over the Australian region and New Zealand during the 20th century. Clim Change 42:183-202

Repapis X (1975) On the hot invasions to the higher troposphere in Greece. PhD thesis, University of Ioannina

Rayner JN (1971) An introduction to spectral analysis. Pion, London

Ross SM (1985) Introduction to probability models. Academic Press, Orlando

Sanderson M (1983) Heating degree days research in Alberta. Residents conserve natural gas. Prof Geogr 35:437-440

Waylen PR, LeBoutillier DW (1988) Analysis and prediction of abnormally cold spells in southern Saskatchewan. Can Geogr 32(3):223-236

WMO (1983) Guide to climatological Practices. Tech Note No 111, World Meteorological Organization, Geneva

Zambakas J (1981) General climatology. University of Athens

Submitted: April 4, 2004; Accepted: November 4, 2004

Proofs received from author(s): December 7, 2004 